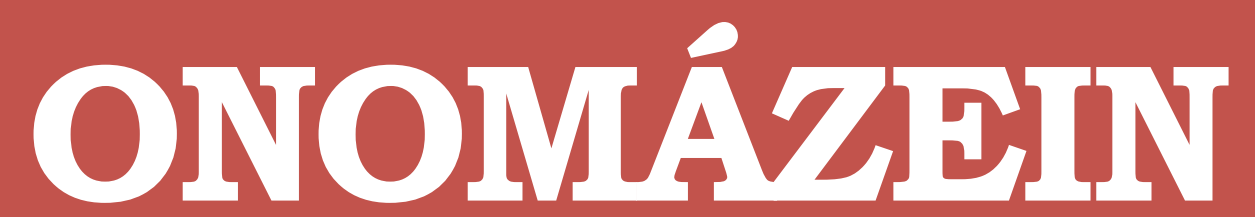

Revista de lingüística, filología y traducción
PONTIFICIA UNIVERSIDAD CATÓLICA DE CHILE FACULTAD DE LETRAS

\title{
Interacción discursiva y fórmulas de tratamiento en las respuestas de los hoteles a las opiniones de viajeros ${ }^{1}$
}

Discursive interaction and forms of address in hotels' responses to traveller's opinions

Número especial

- IV -

Apelación en el discurso digital

2018

\section{Julia Sanmartín Sáez}

Universitat de València

España

ONOMÁZEIN - Número especial IV: Apelación en el discurso digital (octubre de 2018): 119-141

DOI: 10.7764/onomazein.add.01

ISSN: 0718-5758

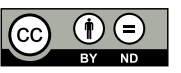

Julia Sanmartín Sáez: Departamento de Filología Española / Instituto Interuniversitario de Lenguas Modernas Aplicadas (IULMA)/Grupo VALESCO,Universitat deValència, España. | Correo electrónico:julia.sanmartin@uv.es 


\section{Resumen}

Este artículo analiza la diversidad de fórmulas de tratamiento autorreferenciales y vocativas, empleadas por los responsables de 40 hoteles al responder en el buscador de alojamientos TripAdvisor a las opiniones de sus clientes. Se pretende determinar cómo la singularidad de este cibergénero del turismo 2.0, opinión-respuesta, con su tenor funcional y papeles discursivos, incide en la selección de estas fórmulas, categorizadas como estrategias pragmalingüísticas que acentúan la distancia o proximidad entre los interlocutores. Como segundo objetivo, se comprueba si la categoría del hotel y su ubicación en España o en Argentina repercuten también en el empleo de estas fórmulas. Se concluye que el tipo de género discursivo y la categoría del hotel se convierten en parámetros importantes que condicionan su uso.

Palabras clave: fórmulas de tratamiento; papeles discursivos; variación lingüística y cibergénero turístico.

\section{Abstract}

This article analyses different self-address and reader forms of address employed by the people in charge of tourist accommodation establishments when answering the opinions or reviews made by their clients in the TripAdvisor search engine (tripadvisor.es). First, I attempt to determine how the singularity of this cybergenre of tourism 2.0, opinion-answer, with its functional tenor and its discursive roles, affects the selection of the above mentioned forms, categorized as pragmalinguistic strategies that enhance the distance or closeness between the interactants. Secondly, an attempt is made to prove whether the hotel category along with its location in Spain or in Argentina also bear an influence on the enactment of these address forms. It is concluded that the discursive genre type and the hotel category turn into significant elements that condition the employment of these address forms.

Keywords: forms of address; discursive roles; linguistic variation and tourism; cybergenre.

1 Este análisis se ha realizado en el marco del proyecto de investigación, concedido por el Ministerio de Economía y Competitividad de España, La atenuación pragmática en el español hablado: su variación diafásica y diatópica. Proyecto MINECO: FFI2013-40905-P. 


\section{El turismo 2.0 y los cibergéneros como marco de referencia}

La presente investigación se enmarca en el análisis de las estrategias pragmalingüísticas que los hablantes activan al redactar sus discursos electrónicos. De hecho, el estudio de los géneros digitales o cibergéneros se sitúa en la netlingüística, ciberlingüística o ciberpragmática (Yus, 2010), entre otras de sus posibles etiquetas. Y desde esta perspectiva pragmática se incluyen aspectos diversos como la cortesía, las fórmulas de tratamiento y las unidades dialógicas.

Este artículo se centra en las respuestas que recibe el cibergénero discursivo denominado opiniones de viajeros [sobre hoteles], reseñas de hoteles o comentarios sobre hoteles, procedente en cierto modo de la transformación² de los tradicionales libros de visita que los viajeros redactaban al salir de sus hoteles o incluso de las breves encuestas que también los viajeros depositaban en las urnas colocadas para tal efecto. Dicho cibergénero puede alojarse en el marco de la propia página web del establecimiento hotelero o bien en páginas de buscadores de hoteles, como TripAdvisor 〈www.tripadvisor.es〉 o Minube 〈www. minube.com〉. Esta ubicación condicionará las características del producto final.

El cibergénero opinión se sitúa en el ámbito del turismo 2.0, surgido a su vez en el marco de la web 2.0 y considerado como una evolución de los sitios de viajes en internet. Estos sitios favorecen la participación de los usuarios al contar sus experiencias y modificar la decisión de otros usuarios y futuros viajeros (William y Pérez Martell, 2008: 1; Calvi, 2010: 20; González, 2012: 14; Suau, 2012: 144; Piccioni, 2014: 94). De este modo, el ámbito turístico se ha sumado al empleo de las nuevas tecnologías (Domínguez y Araújo, 2012). Instituciones y empresas privadas comercializan y promocionan sus productos a través de la red por sus diversas ventajas: actualización de contenidos, interactividad y colaboración de los usuarios, rapidez, multimedialidad, etc. (Caldevilla, 2010). En este proceso - y aquí radica la innovación-, son los propios clientes o viajeros los que contribuyen a la promoción de los productos turísticos, ya que sus escritos/opiniones circulan por la red y añaden un valor (González, 2012: 14). Sobre este valor añadido insisten los dos buscadores comerciales anteriormente citados, al considerar que las condiciones de verdad de los enunciados vienen aportadas por los testimonios de otros viajeros: así, "las opiniones auténticas al respecto en las que puedes confiar” [...] <www.

2 La clasificación propuesta por Shepherd y Watters en 1998 sobre tipos de géneros (original-espontáneo: nacen con la propia web, como el chat; original-emergente: parten de modelos tradicionales, pero los modifican notablemente; o existente, con o sin variantes: limitados a replicar textos impresos) ha sido aplicada al discurso turístico por González (2012). A nuestro juicio, este cibergénero, si bien en su inicio se podría considerar como emergente porque parte del modelo tradicional de libros de visita o encuesta de valoración del y para el hotel, se aproxima al espontáneo, ya que posee un tenor singular: aconsejar a otros viajeros. Nótese que este consejo público solo es posible a través de la red. 
tripadvisor.es> o "planifica tu próxima escapada: puedes empezar por ver las recomendaciones de viajeros reales en los miles de hoteles que podrás encontrar en minube "[...] <www. minube.com>. En cambio, en la promoción turística clásica (como la página web del hotel), la fuente de enunciación es la propia empresa y su valoración puede estar sesgada por sus intereses comerciales (Sparks y Browning, 2011).

En suma, el cibergénero opinión, enmarcado en el eWOM (electronic word of mouth)3, posee una incidencia abrumadora en el sector económico del turismo y de la hostelería (Ye y otros, 2009; Zhang y Vásquez, 2014: 54; Cañero y otros, 2015), pues repercute directamente en la decisión de potenciales clientes para seleccionar su alojamiento, en sus hábitos de consumo y en la configuración de la considerada como reputación on-line —o en línea-.

\section{Caracterización del objeto de estudio: el género encadenado opinión de hotel y su respuesta como proceso de interacción discursiva}

El género discursivo opinión de hotel se singulariza por estar escrito por emisores que no asumen un papel transaccional concreto, esto es, no son ni empresarios ni fuentes institucionales. Son meros viajeros que emiten opiniones para aconsejar a otros posibles viajeros sobre el propio hotel, objeto de la opinión, con motivaciones que oscilan de lo altruista a lo egoísta: preocupación por los demás, integración en redes sociales o reconocimiento como viajero experto, entre otras, según apunta Piccioni (2014: 96). Por ello, el tenor funcional se encuentra más cercano a lo socializador que a lo transaccional, al no asumirse un papel funcional ni encontrarse en un espacio y tiempo marcados, como podría ser la consulta de un médico y la sala de un juicio. Ahora bien, cabe matizar que esta opinión surge y solo puede emitirse si el viajero ha sido cliente o consumidor de las prestaciones del alojamiento turístico, entre otros motivos, para evitar comentarios negativos de la posible competencia. Desde esta perspectiva, se superpone el papel interaccional de antiguo cliente al de mero viajero comentarista.

Otra cuestión más compleja es la inserción de estas opiniones en otros géneros discursivos - llámense macrogéneros, en Calvi (2010), o géneros soporte, en Sanmartín (2014) - con un claro tenor transaccional: Ios buscadores de alojamientos como TripAdvisor o incluso la página web comercial del establecimiento hotelero. Los buscadores actuarían a modo de género soporte o macrogéneros donde se publican las opiniones.

3 Se trata de la promoción de los productos comerciales, realizada por los consumidores a través de sus comentarios en la red: es como el "boca a boca”, pero electrónico. 
TripAdvisor presenta una articulación en diversas pestañas, con hipervínculos en la parte superior de la interfaz como Inicio, Hoteles, Vuelos, Alquileres, Restaurantes, Qué hacer, Lo mejor de 2012, Mis Amigos o Más. En la entrada de cada hotel, aparece la denominación, la localización, los servicios del hotel, la opción de encontrar el mejor precio en diferentes buscadores, fotos profesionales y de viajeros, el número de opiniones emitidas, los resultados de la puntuación de los viajeros (de excelente a pésimo), la clasificación de las opiniones en función del perfil del usuario (familia, pareja, solitario, negocios), el resumen de las puntuaciones y la selección de las opiniones por fecha, puntuación o lengua.

A su vez, en cada opinión se halla en la parte lateral izquierda la identificación del emisor, su nombre o apodo escogido, lugar de procedencia — con localidad y/o país-, una imagen con la que se simboliza, su nivel de colaboración, el número de opiniones y si han sido útiles. En la parte central, se inserta la opinión precedida de una especie de título que sintetiza el texto posterior y unos círculos para indicar la valoración o puntuación concedida al establecimiento. También se añade una opción para que el lector indique si ha sido útil la opinión o denuncie. La importancia que adquiere el sustantivo opinión como elemento distintivo del género y su recurrencia en las páginas que contienen este discurso hacen que se considere la denominación opinión como preferible a reseña o comentario, constatadas en otros estudios (Piccioni, 2014), si bien es cierto que en las tres etiquetas se focaliza la atención únicamente en la intervención iniciativa del cliente. Tras la opinión del cliente puede figurar la respuesta del establecimiento hotelero con diferentes funciones pragmalingüísticas (agradecer, justificar, etc.), tal y como se observa en el ejemplo (1):

(1)

\begin{tabular}{|c|c|}
\hline $\begin{array}{l}\text { IMAGEN } \\
\text { José O } \\
\text { Colaborador de nivel } 4 \\
\text { A } 38 \text { opiniones } \\
\text { de opiniones } \\
\text { deteles } \\
8 \text { votos útiles }\end{array}$ & $\begin{array}{l}\text { "Boda" } 5 \text { de } 5 \text { estrellas Opinión escrita hace } 4 \text { días NUEVO } \\
\text { Si ya de por si es un hotel con lujo por los cuatro costados, mi } \\
\text { mujer y yo celebramos aquí nuestra boda. Su atención personal, } \\
\text { los detalles hacia nosotros y su ubicación junto a la playa hacen } \\
\text { se este hotel el mejor sitio para una escapada o estancia de lujo. } \\
\text { ¿Útil? W Gracias, José o Denunciar } \\
\text { Luis r, Room Division Manager en Hotel L.A.R.B., respondió a } \\
\text { esta opinión } \\
\text { Estimado José, } \\
\text { Le agradecemos de nuevo el habernos escogido para una } \\
\text { celebración tan especial y queremos trasmitirle nuestra } \\
\text { satisfacción por haber superado sus expectativas. Esperamos } \\
\text { seguir atendiéndoles de nuevo en el futuro, para otros eventos } \\
\text { especiales o sencillamente para una escapada de relax. } \\
\text { Atentamente, Santiago Ramírez- Director de Alojamiento }\end{array}$ \\
\hline
\end{tabular}

El tratamiento temático y conceptual de estos textos se clasifica como no especializado, ya que los clientes-viajeros no son expertos en el sector y su discurso no incluye léxico especia- 
lizado4, como después se ejemplificará con textos concretos. Los destinatarios de la información son otros viajeros anónimos que leen dichos textos, emitidos en un ámbito público. Todos ellos forman parte de una especie de comunidad virtual de viajeros, entre los que existe una relación de + igualdad y - poder. Cabe insistir en que la gestión de las opiniones depende de una especie de moderador o responsable de su publicación. Este moderador anima a los clientes-viajeros a que lleven a cabo esta función de ayuda altruista (aconsejar) a otros viajeros y los caracteriza con la etiqueta de colaboradores (con distintos niveles, según el número de opiniones): "Es más, comparte tú también tu opinión y ayuda a los viajeros de cualquier parte del mundo a planificar y disfrutar de un viaje perfecto" 〈www.tripadvisor.es〉. A veces algunos viajeros expertos asumen cierto papel de especialistas en el ámbito, pero este proceder no justifica ni un tenor transaccional ni el correspondiente léxico especializado.

La posible distancia comunicativa del espacio público mencionado queda neutralizada por la pertenencia del viajero a la comunidad virtual y esto se constata al utilizarse en las opiniones un tono próximo a lo coloquial (la verdad es que, finde, lujazo, super). En las opiniones se tamiza la información a partir de la subjetividad del yo hablante (he estado) o del nosotros como colectivo de los viajeros alojados (hemos estado, nosotros). A veces el yo se sustituye por el tú generalizador (no tienes, andabas). Véanse como muestra las diversas opiniones en (2):

\section{(2)}

Esta normal. He estado cuatro veces, tres por razones profesionales y una privadamente. La verdad es que el hotel está bien, y es difícil encontrar alguna pega, aunque también es difícil destacar algo que lo haga especial. No tienes la sensación de estar en un cinco estrellas Gran Lujo, eso exige algo más, que no ofrece. (Opinión. ESP. 5 estrellas) ${ }^{5}$

Hemos estado este finde y nos ha encantado. Todo perfecto, nuevo, limpio. Nuestro apartamento era un lujazo y a un excelente precio. El personal muy amable y atento. Sin lugar a dudas volveremos a repetir en cuanto haya otro acontecimiento por Alicante. (Opinión. ESP. 5 estrellas)

Baño: Super moderno, supersucio (el suelo parecía gris, pero si andabas con calcetines, resulta que era negro y todo el polvo te lo quedabas tu, algunn pelo en el wáter antes de que lo utilizaramos

4 En este sentido discrepamos de la consideración de Piccioni (2014: 95) como "una nueva forma de comunicación especializada". Para Piccioni, la creación de un molde formal y estable, compartido por la comunidad de usuarios, justifica que se trate de una comunicación especializada y la denominación de reseña, frente a la de opinión. Sin embargo, esta autora en otra parte de su artículo reconoce que se trata de "textos escritos fuera del marco de la comunicación profesional” (2014: 96).

5 Las abreviaturas indican hotel de ESP. (España) o ARG. (Argentina), de 5 estrellas (categoría de 5 y 4 estrellas) o de 1 estrella (categoría de 1 y 2 estrellas). Se han mantenido los textos originales con sus errores ortográficos y gramaticales y se han destacado los elementos mencionados en cursiva. En todos los ejemplos del corpus se han sustituido o suprimido los nombres o denominaciones que permiten el reconocimiento de personas o establecimientos. 
nosotros, ... en fin y encima taaan moderno que no tiene puerta es decir, cero intimidad en el baño, la distancia entre wáter y cama debe ser de 30 centímetros sin puerta de por medio. (Opinión. ESP. 5 estrellas)

Al tratarse de textos escritos, en principio, existe cierta planificación o elaboración del discurso y predomina el elemento textual y verbal frente a la importancia que cobra la imagen visual (fotografías) en otros discursos de la red, como son, por ejemplo, las páginas web de promoción institucional de un país.

Desde la perspectiva de la dinámica interaccional, el emisor de la opinión suele adoptar una identidad anónima, solo reconocible por un mero nombre o apodo. Es anónima porque, con excepción del nivel del colaborador, no existe una garantía de que los datos que ofrece sean auténticos. Puede adoptar un nombre real o ficticio o un apodo, y tanto la imagen real o de ficción como la procedencia geográfica, sexo o edad pueden ser inventados. El anonimato permite escribir una opinión sin dañar la imagen personal del yo.

Este emisor se dirige a un destinatario6, múltiple y anónimo también (los posibles viajeros que leen sus mensajes) — su alocutario, en términos de Kerbrat-Orecchioni (1986) — , aunque el emisor sabe que existe un receptor posible de su mensaje, la dirección del hotel sobre el que se vierte la opinión — su no alocutario. De hecho, su texto no se escribe como una queja explícita dirigida a la recepción. Alude siempre al hotel como objeto de referencia de sus opiniones y no como interlocutor de su mensaje. Solo de un modo indirecto las opiniones son recibidas por la dirección del hotel, puesto que no es el destinatario del mensaje; ;olo es un receptor previsto. Para estos papeles (destinatario o receptor) no existen indicios lingüísticos que permitan su reconocimiento como tales, si no se produce una selección vocativa explícita.

Cabe puntualizar que se considera como destinatario a la comunidad de viajeros porque, según indica el propio buscador TripAdvisor, es a quien se dirige el mensaje de opinión: “Cuen-

6 Diferenciamos tres figuras, simultáneas o no: a) destinatario, a quien va dirigido el texto emitido; admite a su vez nuevas tipologías si se tiene en cuenta la posibilidad de una audiencia o el ser destinatario principal o secundario; b) receptor, quien recibe (descodifica) el texto; c) el sujeto interpelado de un modo explícito (directo) en la enunciación.

7 En cambio, las opiniones que se emiten directamente en la web particular del hotel seleccionan como destinatario al propio hotel.

8 Sobre esta cuestión, reflexiona Vásquez (2011): las quejas se suelen presentar de un modo indirecto en relación con el establecimiento, si bien detecta casos en los que se produce una apelación directa. Por el contrario, en nuestros ejemplos, el hotel no es interpelado de un modo directo. En cualquier caso, compartimos con Vásquez (2011: 1715) que estas opiniones en línea (con audiencia) diluyen la distinción binaria directo/indirecto en la selección del destinatario frente a la clara selección de la interacción oral. 
ta tu experiencia a la gente”, “iNos encantaría conocer tu opinión! Cualquier cosa que puedas compartir ayudará a los demás viajeros a elegir el hotel perfecto para ellos. ¡Gracias!”, “Da un consejo para ayudar a los viajeros a elegir una buena habitación". Sin embargo, no se suele constatar una apelación directa a la comunidad o un pronombre personal (os) en el propio texto de opinión del tipo: "Estimados viajeros, os escribo para recomendaros o desaconsejaros este hotel por las siguientes razones".

Curiosamente, la interacción dialógica solo ha lugar entre la opinión del cliente y la respuesta del representante del hotel, ya que no existen opiniones de clientes que aludan a otras opiniones como par adyacente: tan solo se puede indicar la opción de valorar o puntuar el interés de la opinión vertida. Para Zhang y Vásquez (2014: 55), la respuesta del representante se consideraría como un género encadenado e insisten en su consideración de reacción. Así pues, solo cuando se emite una respuesta del hotel surge el género encadenado, constituido por la opinión y su reacción.

Es el gestor de la página el que permite que el hotel responda a esa opinión, dé lugar a una alternancia de turno y se cierre el único par adyacente posible entre estos dos sujetos, dado que el emisor específico de la opinión de esa intervención iniciativa ${ }^{9}$ no vuelve a emitir una intervención de reacción y ni siquiera queda constancia de que la intervención reactiva del hotel sea atendida desde un punto de vista lingüístico. El gestor puede añadir una indicación para introducir la respuesta del representante del hotel: "Sergio r, Room Division Manager en Hotel L.A.R.B., respondió a esta opinión".

Esa respuesta del representante del hotel implica a su vez dos destinatarios: el sujeto seleccionado de un modo explícito, el cliente que ha vertido una opinión, y el no seleccionado o apelado: el resto de turistas o viajeros que consultan las opiniones para elegir su alojamiento. Obsérvese que, aunque ese colectivo de viajeros son destinatarios implícitos, resultan los más importantes para el representante del hotel: cuando el representante responde, le interesa, sobre todo, no convencer al cliente concreto que haya podido emitir una valoración negativa, sino a la comunidad virtual de lectores/viajeros potenciales ${ }^{10}$. En el caso de las respuestas a opiniones positivas, el destinatario (y sujeto) explícito sería de nuevo el viajero

9 Para el análisis como intervención se utiliza la propuesta de unidades del Grupo Valesco (2014) aplicadas a la segmentación de lo oral. Ahora bien, a diferencia de lo que sucede en lo oral, la mera emisión lingüística (intervención) se convierte siempre en turno en lo escrito. El turno depende del reconocimiento social de la intervención como tal emisión. En el caso de estas opiniones no es viable una nueva emisión lingüística por parte del mismo cliente.

10 Para el hotel su destinatario primordial, a quien se debe convencer de las cualidades positivas, es toda la comunidad virtual de viajeros y no tanto el cliente a quien se responde. De este modo, lo secundario o primordial depende de la perspectiva de la mercadotecnia digital. 
concreto: se le agradece la opinión y se le invita a que vuelva otra vez a alojarse en el establecimiento. En este caso, el resto de la comunidad de viajeros sería el destinatario implícito que comprueba la cortesía valorizadora hacia los clientes en general. Nótese que, cuando la opinión es positiva, el posible viajero que lee la opinión no suele leer la respuesta del hotel; en cambio, cuando la respuesta es negativa, sí se suele leer la justificación, tal y como se ha comprobado al preguntar sobre esta cuestión a 20 sujetos.

Así pues, este género encadenado consta de una sucesión de intervenciones iniciativas o turnos de inicio de los distintos clientes, gestionados por un moderador (el gestor de la web en la que se insertan las opiniones), y unas posibles emisiones de respuesta (intervenciones reactivas o turno de respuesta), que constituyen los sucesivos pares adyacentes que se van añadiendo. Las intervenciones iniciativas proceden de distintos emisores y, generalmente, la intervención reactiva es redactada por el mismo emisor (el representante del hotel). Se consideran solo como posibles emisiones de respuesta porque no siempre tienen lugar, tal y como se observa en el cuadro 1 :

\section{CUADRO 1}

Esquema de la alternancia de intervenciones iniciativas con sus intervenciones reactivas opcionales entre corchetes para constituir pares adyacentes (género encadenado), indicados por la flecha

\section{Buscador de hoteles}

Descripción del hotel

Opiniones gestionadas por el responsable del buscador

Intervención iniciativa/turno de cliente : opinión

个 [intervención reactiva/turno de los viajeros: puntúan el comentario]

[Intervención reactiva / turno del representante del hotely: comentario a la opinión] Intervención iniciativa/turno de cliente ${ }_{2}$ opinión

个 [intervención reactiva/turno de los viajeros: puntúan el comentario]

[Intervención reactiva/turno del representante del hotely: comentario a la opinión]

Desde la perspectiva de los sujetos de la enunciación, la representación gráfica quedaría tal y como se muestra en el cuadro 2, en el que se destaca en negrita el elemento esencial: 


\section{CUADRO 2}

Esquema de enunciadores y destinatarios en opiniones negativas

Enunciador 1: responsable del buscador (gestiona el turno y promueve la opinión)
- Destinatario explícito: tú-cliente (comparte) y comunidad virtual de viajeros (consulta) = (enunciadores 2 y 4 )
Enunciador 2: cliente del hotel (opina y aconseja)
- Destinario implícito : comunidad virtual de viajeros (consulta) $=($ enunciador 4$)$

- Receptor previsto: responsable del hotel (=enunciador 3)
Enunciador 3: responsable del hotel (responde a la opinión)
- Destinatario explícito secundario: cliente del hotel = (enunciador 2)

- Destinatario implícito principal: comunidad virtual de viajeros
Enunciador 4: viajero lector (solo puntúa la opinión)
- Destinatario: cliente del hotel= (enunciador 2)

\section{Las fórmulas de tratamiento en las respuestas a opiniones de estableci- mientos de diversa categoría de España y de Argentina}

En este caso y frente a estudios anteriores centrados en la emisión de la opinión en diversas lenguas (Vásquez, 2011; Tiam, 2013; Piccioni, 2014), en este análisis se abordan las fórmulas de tratamiento utilizadas en la respuesta emitida por los propios establecimientos de alojamiento turístico, como también llevan a cabo Zhang y Vásquez (2014) en relación con quejas en inglés sobre establecimientos chinos. Las recomendaciones del marketing son no dejar una opinión, ya sea positiva o negativa, sin su correspondiente respuesta. De este modo, se cierra el par adyacente, constituido por opinión del cliente y respuesta del hotel. En la red y en soporte impreso tradicional ya proliferan las páginas con consejos sobre cómo elaborar estas respuestas desde la perspectiva del marketing digital. Casi todos ellos coinciden en una serie 
de cuestiones, como contestar a todas las opiniones, sean negativas o positivas, con rapidez para evitar la influencia en otros clientes y asegurar una imagen de responsabilidad, responder de una manera respetuosa y ofrecer soluciones reales que se ejecuten para recuperar la confianza y personalizar cada una de las respuestas.

Todo ello afectará a las fórmulas de tratamiento seleccionadas por el representante del hotel, al que le corresponderá no solo agradecer las opiniones positivas, sino agradecer y justificar las negativas para mejorar su imagen positiva y ser cortés para obtener el éxito conversacional (Briz, 2007).

\subsection{Aspectos metodológicos: la delimitación del corpus}

Las fórmulas de tratamiento responden a las distintas modalidades lingüísticas (pronominales o nominales) que utilizan los hablantes para dirigirse entre ellos (Alba de Diego y Sánchez Lobato, 2009: 13; Fontanella de Weinberg, 1999: 1418), desde una triple orientación: para dirigirse a un destinatario — función vocativa - aludir a un referente — función referencial-o mencionarse a ellos mismos — función de autorreferencia — (Rigatuso 2000: 296). La diversidad de fórmulas de tratamiento se encuentra condicionada, básicamente, por las dimensiones clásicas apuntadas por Brown y Gilman (1960) de poder y de solidaridad, esto es, la consideración de una relación jerárquica asimétrica o no (poder) y la implicación de una relación de camaradería e igualdad o no (solidaridad). Las fórmulas lingüísticas se asocian a estas dimensiones (como tú / usted), si bien sus usos concretos pueden modificarse en el eje diacrónico en sintonía con los propios cambios sociales operados en las comunidades de habla (Calderón, 2010), tal y como atestiguan, por ejemplo, Alba de Diego y Sánchez Lobato (2009) en relación con las formas de tratamiento empleadas por los jóvenes o Rigatuso (2000) en transacciones comerciales de la región bonaerense. También en el eje sincrónico, además de las relaciones jerárquicas y de camaradería, intervienen otros factores como los tipos de actos implicados, los tipos de discursos o las estrategias pragmáticas (Rigatuso, 2000: 299).

En el caso de las opiniones sobre hoteles, existe una relación compleja, puesto que el emisor de la opinión se dirige a sus iguales en la comunidad virtual de viajeros (+solidaridad y -poder) desde la subjetividad del yo o del nosotros, o del tú generalizador, tal y como se ha mostrado en los ejemplos anteriores de (2), siempre amparado en su anonimato. No se suele constatar una apelación directa a esa comunidad de iguales: no aparece explícitamente una apelación al vosotros, que se representaría con un os aconsejo.

Por su parte, el representante del hotel (-solidaridad), con una identificación real y ajeno a esa filiación inicial como viajero, contesta al cliente/viajero. La ausencia de solidaridad indica distancia y también obedece a la asunción de papeles discursivos distintos: el cliente 
del hotel manifiesta su opinión a los iguales como colaborador y el representante del hotel responde como tal: representa al hotel. Cabe insistir en que en esta interacción discursiva virtual el viajero puede actuar con un papel discursivo de colaborador por su relación anterior transaccional de cliente respecto al hotel sobre el que se opina y, por su parte, el representante del hotel responde al viajero-cliente como elemento aludido en la opinión y representante del alojamiento, aunque no sea el destinatario de la opinión. En esta dinámica discursiva, la gestión del turno queda en manos del moderador de la página. Por último, la dimensión digital del discurso, con receptores múltiples, como si de un espacio de un medio de comunicación se tratara, implica la existencia de una recepción discursiva similar a la de una audiencia.

Para comprobar qué tipo de fórmulas de tratamiento aparecen, se ha diseñado un corpus, constituido por respuestas de 40 establecimientos hoteleros: 20 establecimientos de España (ubicados en la Comunidad Valenciana) y 20 de Argentina (ubicados en Buenos Aires), clasificados a su vez en dos tipos de establecimientos: 10 de elevada categoría (5 y 4 estrellas) y 10 de inferior categoría y, generalmente, de dimensión menor.

Se ha establecido esta distinción para obtener la mayor disparidad de resultados entre los establecimientos, teniendo en cuenta su categoría - e indirectamente el tamaño-, y no se ha tenido en cuenta el nivel intermedio, de tres estrellas. Se parte de la hipótesis ${ }^{11}$ de que en los de elevada categoría existirá cierta distancia con el cliente frente a los hoteles de menor categoría y tamaño más reducido en los que será posible mayor proximidad con el cliente.

Esto supone un total de 40 hoteles revisados, escogidos, además, por presentar el mayor número posible de respuestas. Se han revisado de 10 a 200 respuestas en español ${ }^{12}$ por establecimiento analizado, en función de los datos reales hallados en cada establecimiento.

Así pues, se establecen dos variables iniciales como factores determinantes en la selección lingüística: la ubicación geográfica (de España - península - y de Argentina) y la categoría de establecimiento. En principio, se seleccionaron las respuestas a opiniones negativas

11 Esta hipótesis se ha construido a partir del conocimiento previo que se tenía de la tipología de hoteles y de sus correspondientes páginas web, obtenido al elaborar una base de datos con un corpus de 500 páginas web de hoteles de diferentes categorías en el marco del proyecto de investigación COMETVAL (Corpus Multilingüe de Turismo de la Universitat de València).

12 Se debería tener en cuenta lo internacional del género, esto es, la participación de clientes en diversas lenguas. De hecho, Google ofrece una traducción inmediata de las opiniones, y también respuestas de los representantes del hotel en diferentes lenguas. Sobre esta dimensión internacional del género y su repercusión lingüística reflexiona Piccioni (2014) al postular la influencia del tipo de modelo internacional sobre la especificidad de las diferentes lenguas en relación con la opinión. 
para reducir el corpus en los hoteles de categoría superior, si bien en algunos hoteles de inferior categoría se analizaron todas las opiniones para obtener un corpus de mayor tamaño. Por ello, se comprobó si en los hoteles de elevada categoría la fórmula de tratamiento cambiaba en función de si se respondía a una opinión negativa o positiva: en estos últimos, el tono y formalidad en la respuesta se mantenía con independencia del tipo de valoración.

En síntesis, este estudio asume, como otros precedentes (Rigatuso, 2000; Calderón, 2010; Hummel y otros, 2010), una perspectiva sociolingüística con integración de aspectos del análisis de la conversación y de la pragmática.

\subsection{Datos del análisis del corpus}

La estructura de la respuesta se asemeja a un intercambio de tipo epistolar formal -véase el ejemplo 1 - , con un encabezado inicial dirigido al destinatario, un cuerpo del texto con diferentes funciones argumentativas y movimientos retóricos reiterados, como agradecer, justificar o invitar, y una despedida final con identificación del que escribe. La repetición de estos movimientos retóricos y su elevada ritualización, con variantes, ya ha sido constatada en un estudio anterior (Zhang y Vásquez, 2014). Se incluyen en la ritualización epistolar los adjetivos calificadores (estimado) que se configuran como fórmulas fijas rutinarias. Del mismo modo, se ha constatado la voluntad de algunos representantes de los hoteles en mostrar esas respuestas variadas y originales que no se limiten a una reproducción de un texto estándar. Esto último indicaría una falta de atención personalizada para cada cliente. Así, por ejemplo, frente a fórmulas de despedidas reiteradas en algunas respuestas, como atentamente, sorprende el intento de variación por parte de otros responsables. Esto implicaría un distinto grado de formalidad (un saludo, saludos cordiales, sinceramente, cordialmente, reciba un cordial saludo, cariños, muy atentamente, atentamente). Véanse estas dos respuestas del mismo establecimiento argentino de una estrella como muestra de una respuesta con variaciones:

\section{(3)}

Hola Doris! Muchas gracias por tu comentario, te agradecemos habernos elegido para tu estadía en Buenos Aires. Te esperamos pronto! Saludos cordiales, El staff.

Hola Silvina! Muchas gracias por tus comentarios y por habernos elegido. Te esperamos nuevamente en nuestro Hostel. Saludos!

En la presente investigación, como ya se ha indicado, el emisor de la opinión de la intervención inicial no suele identificarse con su nombre y apellidos reales, por lo que estos no suelen figurar en la intervención reactiva del responsable del hotel - a diferencia de lo que sucede en (3)-, especialmente, cuando el emisor se reconoce por un apodo. Como nombre propio, 
real o ficticio, se registran Toni C. o Sergio M., y, como apodo, almerienseviajero, boysfreedom, MadridMia, etc. En cuanto a las imágenes, predominan las que representan paisajes o imágenes ficticias (animales, personajes de ficción, etc.). En cambio, el representante del hotel siempre se suele identificar por el cargo profesional que asume (Guest Relation Manager, Director General, General Manager, etc.) y nombre y apellidos reales.

A continuación, se presenta un cuadro simplificado (3) con las posibles formas vocativas y de autorreferencia atestiguadas en la respuesta del hotel, teniendo presente, por un lado, que en español no suele aparecer el pronombre personal sujeto [tú-vos / usted] como elemento explícito y, por otro, el sistema voseante argentino [vos/usted] con reducción en el plural [vosotros/ustedes] a una única forma [ustedes]:

\section{CUADRO 3}

Síntesis de formas vocativas y de autorreferencia

Fórmulas vocativas (dirigidas al cliente)

Fórmulas nominales

- Términos de tratamiento ocupacionales: estimado cliente, estimado huésped

- Nombre personal: nombre, apodo

Formas pronominales: forma verbal de tercera persona, a veces con [usted] y pronombres personales átonos y posesivos de tercera persona (le(s) / su(s) frente a la forma verbal de segunda persona, a veces con [tú o vos] y pronombres personales átonos y posesivos de segunda persona [te, os, tu(s)]

Fórmulas de autorreferencia (del que escribe la respuesta)

Fórmulas nominales

- Términos de tratamiento ocupacionales: director, gerente, responsable

- Nombre personal: apellido / nombre más apellido

Formas pronominales: forma verbal de primera persona singular [yo], plural [nosotros] o forma verbal de tercera persona [el hotel]

En cuanto a las formas de autorreferencia del representante del hotel, cabe concluir que se suele emplear la primera persona del plural [el nosotros] como representación del hotel en general y un modo de acentuar la identidad corporativa (Zhang y Vásquez, 2014) en acciones como agradecer, invitar de nuevo, justificar o comprobar lo sucedido; y se usa sobre todo la primera del singular [el yo] para indicar actuaciones concretas del que contesta, como ofrecer un contacto personal — solo un hotel de 1 estrella utiliza de un modo explícito el pronombre yo, reproducido en el ejemplo 6-, con independencia de la ubicación y categoría del hotel: 
(4)

Estimado Juan, Muchas gracias por sus comentarios. Nos alegra saber que ha disfrutado de las comodidades y de la ubicación del hotel pero nos gustaría tener mas detalle en referencia al trato de la Recepción. Estoy enviando un mensaje privado para que pueda contactarme. Lo esperamos en otra oportunidad. Cordialmente, C. V. Gerente de Recepción (Respuesta. ARG. 5 estrellas)

Estimado cliente, Le agradecemos su tiempo en escribir una opinión en Tripadvisor. Agradecemos su fidelidad a $\mathrm{H}$ hotel y ser miembro del programa de puntos $X$. Lamentamos que la decoración art deco del hotel no sea de su agrado. Para nosotros la seguridad de nuestros clientes es esencial y por tanto antes de entregar copias de llaves de habitaciones o activar zonas de acceso a clientes es imprescindible identificarse con nuestro personal de recepción, lamentamos que esto haya sido un inconveniente durante su estancia. No dude en contactarme para su próxima visita y me ocupare personalmente de sus peticiones para que su estancia este acorde a sus expectativas.

Saludos Cordiales, C. V. Guest Service Manager (Respuesta. ESP. 5 estrellas)

Ahora bien, es cierto que, sobre todo en hoteles de inferior categoría, se observa que, al redactar la respuesta el propietario del hotel, puede aparecer con mayor frecuencia la primera persona del singular (lamento) más allá del ofrecimiento personalizado de un contacto, combinada con el plural (tuvimos, nos ocasionó, hemos solventado, lo sentimos). Nótese, además, el recurso a la intensificación gráfica por medio de mayúsculas o la repetición del signo ortográfico, habitual de la escritura informal (y próxima) en la red:

(5)

X Hoteles, Propietario en X Valencia, respondió a esta opinión

Lamento leer este comentario. Y además lo que más lamento es que tienes toda la razón. Tuvimos un serio problema con el personal de limpieza que nos ocasionó tener fallos puntuales que ya hemos solventado. De todo corazón. LO SENTIMOSiiii (Respuesta. ESP. I estrella)

En relación a las fórmulas vocativas de tratamiento y la incidencia de las dos variables señaladas, los resultados del estudio son los que a continuación se indican. Los hoteles de elevada categoría solo emplean la tercera persona [usted] (100\%), tanto en España como en Argentina; en cambio, los hoteles de inferior categoría alternan la tercera persona [usted] con la segunda persona [tú o vos] de forma bastante similar en las dos zonas geográficas: en España, la segunda persona [tú] (40\%) y la tercera persona [usted] (50\%), o ambas formas en el mismo hotel y en la misma respuesta (10\%); en Argentina, la segunda persona [vos] (40\%), la tercera persona [usted] (30\%) y ambas formas en el mismo hotel (30\%). Obsérvese en el ejemplo (6) una muestra de este último tipo de alternancia en un mismo hotel de España, entre el tú (tu crítica, comentarte), referido al cliente que ha escrito la opinión, y el ustedes (les pedimos, les pregunté, ustedes me comentaron), abarcador del grupo de clientes alojados en esa estancia: 
(6)

Hola, al ver tu crítica me gustaría comentarte algunas cuestiones. En nuestro caso, somos un hotel pequeño y no tenemos servicio de maletas, les pedimos disculpas si esto fue un inconveniente. En cuanto al Cava, no es que lo olvidáramos, al contrario, yo misma les pregunté a qué hora llegarían para tenerlo preparado y ustedes me comentaron que se los pusiera después de cenar [...]. (Respuesta. ESP. 1 estrella)

La tercera persona [usted] de distancia se refleja en las formas pronominales (como su opinión), pero no suele aparecer explícito el pronombre usted, a no ser en casos como la introducción de personas en el relato de la opinión anterior o en el ejemplo posterior:

\section{(7)}

Gracias por el comentario, siempre esperamos mejorar para que la próxima estadía usted otorgue 4/5. Gracias. (respuesta ARG. 1 estrella)

Solo en raras ocasiones se ha atestiguado la abreviatura Ud., como en (8):

(8)

Buenos días, Gracias por transmitirnos su opinión que es una oportunidad de mejora para nosotros, valoraremos cada punto por Ud. Expuesto (Respuesta. ESP. 5 estrellas)

En este estudio se ha partido de un modelo dual de fórmulas vocativas pronominales (proximidad, con pronombres y formas verbales de segunda persona, y distancia, con pronombres y formas verbales de tercera persona) y, además, se ha tenido presente el sistema voseante ${ }^{13}$ argentino (Calderón, 2010: 230), si bien no se han documentado apenas el pronombre explícito vos ni sus correspondientes formas verbales, como tampoco se han registrado el resto de formas correspondientes al pronombre personal sujeto (tú/usted), tal y como ya se ha indicado al inicio de este apartado. Téngase en cuenta que en las respuestas solo aparecen de forma explícita las fórmulas nominales (estimado huésped) y las formas personales posesivas (su/ tu) o de objeto (le/te):

13 La norma culta del sistema del español de Argentina, y en especial de Buenos Aires, es un paradigma verbal y pronominal mixto: con formas voseantes en presente de indicativo (cantás) e imperativo (cantá) y con formas tuteantes en el resto, y con uso de vos en lugar de tú, como sujeto, vocativo y término de la preposición, y formas de tuteo, como te, tu y tuyo, en el resto. Véanse, al respecto, Fontanella de Weinberg (1999: 1409), Rigatuso (2000) o una síntesis en RAE (2005). Téngase en cuenta que este voseo pronominal, como paradigma mixto y forma verbal de confianza, aparece en los ejemplos de 9, 10 y 11; y en el ejemplo 10 también se constata una forma verbal correspondiente a este paradigma mixto que incluye formas tuteantes.

Agradecemos las matizaciones sobre este aspecto realizadas por Elisabeth Rigatuso. 
(9)

Estimada Valentina, Es un placer saludarte desde H. Buenos Aires. Muchas gracias por compartir tu experiencia en nuestro hostel. Lamentamos no haber cumplido con tus expectativas, trabajamos con seriedad para que el hostel este limpio y en condiciones, los comentarios de nuestros huéspedes avalan la limpieza de $\mathrm{H}$. asi como nuestro servicio y atención. Esperamos poder revertir tu experiencia en alguna otra oportunidad, Saludos, Daniel (Respuesta, ARG. 1 estrella)

En general, en las respuestas aparecen las formas vocativas en singular, con lo que se ha soslayado la neutralización de ustedes como formal e informal en Argentina, frente al sistema dicotómico del español peninsular de España, diferenciador de vosotros/ustedes. Se ha detectado alguna recurrencia de este uso neutralizado argentino en plural, como muestra el ejemplo (10) en para ustedes, y, por ello, solo se han podido tener en cuenta las formas del singular (en te hayas) de la misma respuesta para evaluar la distancia o proximidad respecto al interlocutor:

(10)

Gracias por tomarte el tiempo de escribir sobre Xhotel. Nos alegra que te hayas podido sentir a gusto en nuestro XX, como en casa! Ese es nuestro objetivo! Lograrlo para ustedes es nuestra mayor satisfaccion. Estamos acá para ayudarte y simplificarte la estadía para que puedas disfrutarla sin inconvenientes. Nos encantaría verlos de vuelta pronto! Los estaremos esperando

(Respuesta. ARG. 1 estrella)

De este modo, se concluye que, en las respuestas a las opiniones, los responsables hoteleros de establecimientos de categoría superior prefieren de forma mayoritaria mantener una distancia comunicativa y una formalidad en el tono, en especial, porque su intervención reactiva es indirecta, dado que la opinión del colaborador de TripAdvisor no lo selecciona como destinatario explícito de su emisión, y, además, porque su respuesta se establece a partir de su papel funcional como representante del hotel; de hecho, el representante firma como tal al final de su intervención (Juan Pérez. Gerente del hotel) y lo reitera en ocasiones el propio gestor de TripAdvisor (Emisión emitida por el gerente del hotel), como si de un intercambio epistolar convencional se tratara. Se asimilan, pues, unas normas de cortesía convencionalizadas en estas situaciones (Briz, 2007). Solo los establecimientos hoteleros de categoría inferior o de dimensiones menores se permiten establecer una proximidad comunicativa con ese colaborador, tal y como se plasma en la propia respuesta. A veces la estancia ha posibilitado una relación más personal, como se comprueba también en (10), y, de ahí, esta forma de tratamiento:

\section{(11)}

X Hoteles, Propietario en X Valencia, respondió a esta opinión

Lamento leer este comentario. Y además lo que más lamento es que tienes toda la razón. Tuvimos un serio problema con el personal de limpieza que nos ocasionó tener fallos puntuales que ya hemos solventado. De todo corazón. LO SENTIMOSiiii (Respuesta. ESP. I estrellas) 
Estimado Jonathan, Es un placer saludarlo desde X Hostel-Buenos Aires. Muchas gracias por compartir tu experiencia en nuestro hotel. Nos pone muy felices saber que pasaron una excelente estadía con nosotros. Esperamos recibirlos muy pronto nuevamente! Saludos, Carlos (Respuesta. ARG. 1 estrella)

Estimada Raquel, Muchas gracias por compartir tu experiencia en nuestro hostel. Lamentamos no haber cumplido con tus expectativas y esperamos tener la oportunidad de revertir tu opinión en algún otro momento. [...] Cualquier duda estamos a tu disposición, Cariños, Carlos (Respuesta. ARG. 1 estrella)

La aproximación con el cliente también se refuerza con las fórmulas de despedida o con los emitoconos, cuando es la segunda persona [tú o vos] la variante seleccionada frente a la tercera persona [usted], en este tipo de establecimiento, en especial cuando se presentan opiniones no consideradas como negativas:

(12)

Muchas gracias Maria Lucia, Me alegro que te sentiste como en casa, es lo que quise hacer con X ;-) Fue un placer conocerte, a ver si voy con mi mama a conocer Rosario en 2016 ! Saludos cordiales. Gregorio (Respuesta. ARG. 1 estrella)

Gracias Lu! Muy linda tu descripción! Estamos felices por haber cumplido con nuestro objetivo, hacerlos sentir como en casa! Te esperamos prontito :) Saludos!

(Respuesta. ARG. 1 estrella)

Esta aproximación o distancia comunicativa se construye también con las fórmulas de tratamiento nominales, en las que se aprecian varias cuestiones. En los hoteles de superior categoría en España predomina (85\%) la consideración del colaborador a partir de la relación comercial contraída con anterioridad, de ahí la denominación mayoritaria de estimado cliente. En los hoteles de superior categoría en Argentina, también se considera esta relación, si bien en menor grado (40\%) y con una fórmula distinta, estimado huésped, y se alterna con el nombre propio o apodo del colaborador, precedido de hola, buenos días o estimado y estimado sr., y con la ausencia de una designación específica (20\%). En todos estos casos, téngase en cuenta que se establece la tercera persona [usted] de distancia como predominante.

En el caso de los hoteles de inferior categoría y tamaño, se prefiere el nombre propio o apodo o la ausencia de tratamiento nominal. Así, en estos hoteles españoles se emplea el nombre o apodo (20\%), el tratamiento como cliente (10\%), ambos a la vez (20\%), el tratamiento como colaborador (10\%) y, de forma mayoritaria, se omite la designación nominal (40\%). Por su parte, en los hoteles argentinos se observa una situación similar: el tratamiento como huésped (30\%), como huésped y nombre propio (10\%), como nombre o apodo, precedido de buenos días, hola o estimado (30\%), sin ninguna forma de tratamiento (20\%) y combinados estos dos últimos (10\%). Cuando se emplea la forma de tratamiento de cliente o huésped 
siempre se acompaña de la tercera persona [usted]; en cambio, en las otras formas nominales o en ausencia, se combinan la tercera [usted] (lo haya pasado) y segunda persona [tú o vos] (puedas visitarnos, tu lado, te convendría) e, incluso, en algún caso aparece explícita la forma vos, si bien con valor de generalización (vos alquilas):

(13)

Estimada, lamentamos que lo haya pasado tan mal, nos esforzaremos mas para la proxima vez que puedas visitarnos, Sin que se mal entienda, quiero explicarte que los hostels alquilan solo las camas y a tu lado puede estar durmiendo un desconocido, en un hotel vos alquilas la habitacion , que puede ser con baño privado o sin baño privado, la proxima vez te convendria estar en un cuarto con baño privado, cuesta un poquito mas y es mucha la diferencia. Saludos Jose (Respuesta. ARG. 1 estrella)

Resulta singular y recurrente el uso incorrecto, desde la perspectiva normativa, de la mayúscula en la denominación Estimado Huésped o Estimado Cliente. Se podría considerar como una estrategia para individualizar y otorgar mayor consideración al sujeto. Desde esta perspectiva normativa, sorprende también la falta de tilde que presentan en general los textos, en especial, cuando afecta de manera recurrente a la palabra huesped. Esta es la palabra que predomina en Argentina:

(14)

Estimado Oscar L, buenas tardes. Muchas gracias por sus comentarios. Para nosotros ha sido un placer tenerlos como huespedes en X Buenos Aires Hotel. El valor de todas las cocheras aqui en el centro suele ser elevado si lo comparamos con las que no están ubicadas en la zona del centro Esperamos nos visite pronto nuevamente. Saludos (Respuesta. ARG.5 estrellas)

También se aprecian variantes de estilo, sobre todo en las fórmulas rutinarias de despedida(Con atentos saludos quedo a su más entera disposición), relacionadas con la variación diatópica y con una cortesía altamente convencionalizada y un estilo más poético (Nuevamente le agradezco el haberse tomado el tiempo para regalarnos su opinión) en Argentina frente a España:

(15)

Estimada Sra. X: Espero tenga muy buenos dias. Lamento muchisimo que su estadia en nuestro hotel no se haya correspondido con sus expectativas. Le aseguro que vamos a hacer todo lo posible para que, en caso de que decida volver a visitarnos, podamos mejorar su percepcion. [...] Con atentos saludos quedo a su mas entersa disposicion. Cordialmente. XXX Director General X La Reserva X (Respuesta. ARG.5 estrellas)

Estimado/aXX: Antes que nada agradezco se haya tomado el tiempo de ofrecernos una opinion respecto de nuestro hotel. Nuestra vision en $X$ es que el huesped siempre tiene razon y es por eso que aceptamos sus criticas y con sus comentarios trabajaremos en evitar nuevas ocurrencias de este tipo. 
No puedo no obstante solicitarle si es usted tan amable me ayude brindandonos mas precisiones respecto de en que fecha y habitacion se alojo usted con nosotros y algun dato adicional que nos pueda ayudar a dilucidar que fue lo que sucedio.

Nuevamente le agradezco el haberser tomado el tiempo para regalarnos su opinion.

Para el caso de que desee enviarnos algun tipo de informacion le dejo mi mail $X$, caso contrario le pido mis mas sinceras disculpas por el momento vivido y quedo a su entera disposicion para una futura visita. Cordialmente. XXX Director General XXHotel (Respuesta. ARG.5 estrellas)

Tanto en España como en Argentina el sexo del cliente no determina ningún cambio en la forma de tratamiento establecida por el representante del hotel. En algunas ocasiones se emplea el masculino para aludir a una mujer, lo cual debería evitarse puesto que parece que responda a una fórmula rutinaria repetida sin singularizar la respuesta:

(16)

Colaborador (Lorena)

Respuesta: Estimado Cliente, Primeramente nos gustaría agradecerle que haya elegido el $\mathrm{X}$ hotel para su circuito SPA. (Respuesta. ESP.5 estrellas)

Del mismo modo, a veces se usa estimado/a cuando no se tiene la certeza del sexo a que corresponde el apodo del colaborador.

\section{Síntesis de resultados del análisis}

El estudio realizado en una muestra de 40 establecimientos hoteleros de España y de Argentina indica el modo distinto en que repercuten las dos variables establecidas (categoría y país del establecimiento) en las fórmulas de tratamiento implicadas en las respuestas que los establecimientos ofrecen a las opiniones de los clientes a modo de género encadenado.

Se confirma que la categoría del establecimiento hotelero es una variable esencial que determina tanto la fórmula de tratamiento pronominal como la nominal. De este modo, los hoteles de categoría superior optan por usar la tercera persona de formalidad [usted] con el colaborador de TripAdvisor, y en la mitad de las ocasiones, en especial en España, mantienen su consideración como cliente o huésped. Por el contrario, los establecimientos de inferior categoría prefieren combinar la tercera persona [usted] con la segunda persona [tú o vos], incluso para dirigirse al mismo cliente, como aproximación y cercanía con ese colaborador, y no suelen aludir a su categorización derivada de su relación comercial. No ha sido posible detectar la forma pronominal vos porque en las respuestas solo aparecen formas pronominales posesivas (tu/su estadía) y de objeto (le/te agradecemos), pero no se documentan empleos 
como sujeto o como complementos con preposición. Se suele tratar, en definitiva, de una respuesta epistolar de saludo, agradecimiento y justificación.

La variable de zona geográfica solo interviene para determinar la selección léxica nominal mayoritaria (cliente/huésped) y en el predominio aludido de la consideración del colaborador como cliente en los hoteles de superior categoría en España, si bien el discurso retórico y el estilo son bien distintos en las dos zonas geográficas y exigen un estudio específico.

Por su parte, el representante del hotel, en su propia autorreferencia, emplea el nosotros para englobar al establecimiento comercial, y solo cuando suele asumir una actividad específica incorpora la primera persona del singular o cuando se trata de un establecimiento de inferior categoría (lamento).

Finalmente, más allá de las dos variables seleccionadas, las fórmulas de tratamiento en la respuesta del representante del hotel también se encuentran condicionadas por la propia dinámica discursiva. El representante no se considera como destinatario de la opinión del cliente. Este cliente escribe desde la protección de su anonimato, con su apodo, y desde la acentuada subjetividad del yo para aconsejar a otros viajeros, múltiples y anónimos, sus pares en la comunidad de viajeros. La figura discursiva del representante se reduce a un mero receptor previsto: de ahí que su respuesta sea complicada desde la perspectiva argumentativa, especialmente cuando responde a una opinión negativa.

Sin duda, los papeles discursivos adquieren cierta complejidad en este entramado de comunicación electrónica: el representante responde a un cliente, considerado como destinatario - no principal pero apelado de un modo explícito-, si bien intenta convencer a una comunidad de viajeros, concebida como una especie de audiencia, principal destinataria de su respuesta. Escribe esta respuesta como si de una especie de género epistolar se tratara y se vale de diferentes estrategias de aproximación o distancia en una dinámica de interacción comunicativa altamente ritualizada a pesar de su reciente aparición. Se intenta contrarrestar la valoración negativa a través de una serie de actos sucesivos: saludar, agradecer la opinión, comprobar lo sucedido, adoptar las medidas en caso de que proceda y despedirse, todo ello de un modo personalizado y sin que parezca que la respuesta es la misma para todas las críticas.

En suma, los discursos electrónicos plantean unas coordenadas de enunciación singulares y novedosas, condicionadas en numerosos casos por el anonimato del sujeto emisor que escribe desde la subjetividad del yo y por la recepción múltiple con posibilidad de intervención reactiva. Todo ello inscrito en un soporte gráfico y permanente, a modo de registro de las nuevas formas de interacción. Los establecimientos hoteleros, desde su nosotros como entidad empresarial o desde el yo de su actuación concreta, perfilan lingüísticamente en función de su categoría distintas estrategias de proximidad o distancia con sus clientes o huéspedes. 


\section{Bibliografía citada}

Alba de Diego, Vidal, y Jesús Sanchez Lobato, 2009: "Tratamiento y juventud en la lengua hablada. Tratamiento sociolingüístico" en Jesús Sanchez Lobato y otros (eds.): Aspectos del español actual: descripción, enseñanza y aprendizaje (Lıy L2), Madrid: SGEL, 13-43.

BRIz, Antonio, 2007: "Para un análisis semántico, pragmático y sociopragmático de la cortesía atenuadora en España y América”, Lingüística Española Actual 29 (1), 5-40.

Brown, Roger, y Albert GiLman, 1960: "The pronouns of power and solidarity" en Thomas Sebeok (ed.): Style in Language, New York: Cambridge University Press, 253-275.

Calderón, Miguel, 2010: "Formas de tratamiento" en Milagros Aleza y José Manuel Enguita (coords.): La lengua española en América: usos y normas actuales, Valencia: Universitat de València, 225-236.

Caldevilla, David, 2010: "Las Redes Sociales. Tipología, uso y consumo de las redes 2.0 en la sociedad digital actual”, Documentación de las Ciencias de la Información 33, 45-68.

Calvı, Maria Vittoria, 2010: "Los géneros discursivos en la lengua del turismo: una propuesta de clasificación”, Ibérica 19, 9-32.

Cañero, Pablo, y otros, 2015: "Reputación online de los Hoteles de Sol y Playa en la República Dominicana”, Cultur. Revista de Cultura y Turismo 3, 86-100.

Dominguez, Trinidad, y Noelia Araújo, 2012: "El fenómeno 2.0 en el sector turístico. El caso de Madrid 20", Pasos. Revista de Turismo y Patrimonio Cultural 10, 225-237.

Fontanella, Ma Beatriz, 1999: "Sistemas pronominales de tratamiento usado en el mundo hispánico" en Ignacio Bosque y Violeta Demonte (dirs.): Gramática descriptiva de la lengua española, Madrid: Espasa, 1400-1425.

GonzAlez, Virginia, 2012: "El discurso del turismo en Internet: hacia una caracterización de sus géneros” en Julia Sanmartín (ed.): Discurso turístico e Internet, Madrid: Iberoamericana, 13-50.

Grupo Valesco, 2014: "Las unidades del discurso oral. La propuesta Val.Es.Co. de segmentación de la conversación coloquial”, Estudios de Lingüística del Español 35 (1), 11-71.

Hummel, Martin, y otros (eds.) 2010: Formas y fórmulas de tratamiento en el mundo hispánico, México: El Colegio de México.

Kerbrat-Orecchioni, Catherine, 1986: La enunciación. Buenos Aires: Hachette.

PICCIONI, Sara, 2014: “Cortesía y lenguas de especialidad entre lo local y lo global: el caso de las reseñas de hoteles en español einglés”, Normas. Revista de Estudios Lingüísticos Hispánicos 4, 93-116. 
Real Academia Española, 2005: Diccionario panhispánico de dudas, Madrid: Santillana.

Rigatuso, Elisabeth M., 2000: “'Señora (...) ¿No tenés más chico?” Un aspecto de la pragmática de las fórmulas de tratamiento en el español nonaerense", Revista Argentina de Lingüística $16,293-344$.

Sanmartín, Julia, 2014: "A propósito de los cibergéneros: el Portal Oficial de turismo de España de Spian.info y el Facebook institucional See.spain como objeto de análisis", Lingüística Española Actual 36, 119-148.

Shepherd, Michael, y Carolyn Watters, 1998: "The Evolution of Cybergenres" en Ralp Sprague (ed.): Proceedings of the 3Ith Annual Hawaii International Conference on System Sciences, Los Alamitos (CA): IEEE-Computer Society, 97-109.

Sparks, Beverley A., y Victoria Browning, 2011: "The impact of online reviews on hotel booking intentions and perception of trust", Tourism Management 32, 1310-1323.

SuAu, Francisca, 2012: "El turista 2.0 como receptor de la promoción turística: estrategias lingüísticas e importancia de su estudio", Pasos 10 (4), 143-153.

TIAm, Youfei, 2013: "Engagement in online hotel reviews: A comparative study", Discourse, Context \& Media 2 (4), 184-191.

Willam, Edu, y Esther Pérez Martell, 2008: "Turismo 2.0. La Web social como plataforma para desarrollar un ecosistema basado en el conocimiento" en Actas del VII Congreso Turismo y Tecnologías de la Información y las Comunicaciones [http://www.turitec.com/actas/2008/16_ Turismo_20.pdf, fecha de consulta: 5 de diciembre de 2016].

YE, Qiang y otros, 2009: "The impact of online user reviews on hotel room sales", International Journal of Hospitality Managemen 28, 180-182.

Yus, Francisco, 2010: Ciberpragmática 2.0, Barcelona: Ariel Letras.

Vasquez, Camilla, 2011: "Complaints online: The case of TripAdvisor", Journal of Pragmatics 43, 1707-1717.

Zhang, Yi, y Camilla Vasquez, 2014: "Hotels'responses to online reviews: Managing consumer dissatisfaction", Discourse, Context and Media 6, 56-64. 